\title{
Duodenal Crohn's disease successfully treated with adalimumab
}

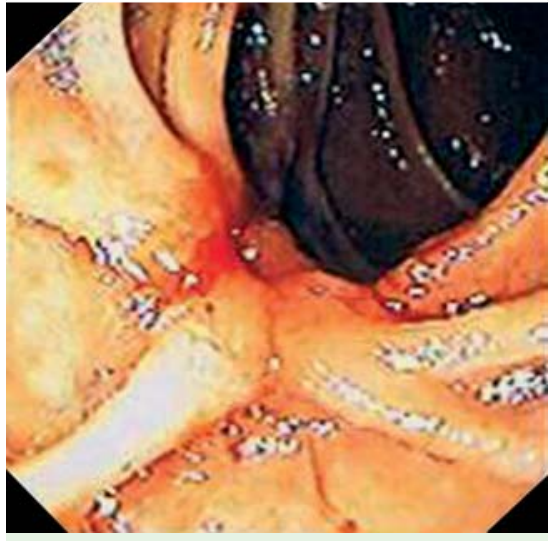

Fig. 1 Endoscopic appearance of the second portion of the duodenum before treatment, showing thickening of some duodenal folds which converge to a large ulcer with thickened margins and spontaneous bleeding.

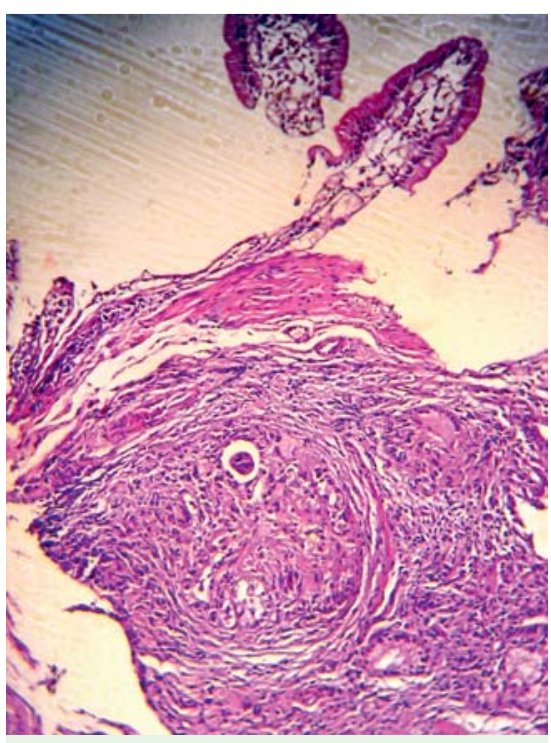

Fig. 2 Histological specimen (hematoxylin \& eosin, $\times 40$ ). A marked transmucosal inflammatory infiltrate is visible, also involving the submucosal layer. A large noncaseous granuloma can be also seen in the middle of the picture, under the epithelial layer.

Upper gastrointestinal involvement in Crohn's disease is considered to be relatively infrequent $(0.4-3 \%)$ [1], and treatment mainly relies on the use of high doses of proton pump inhibitors, mesalazine (mesalamine), and steroids [2].

A 37-year-old woman was admitted for observation in November 2009 because of diarrhea, epigastric pain, iron-deficiency

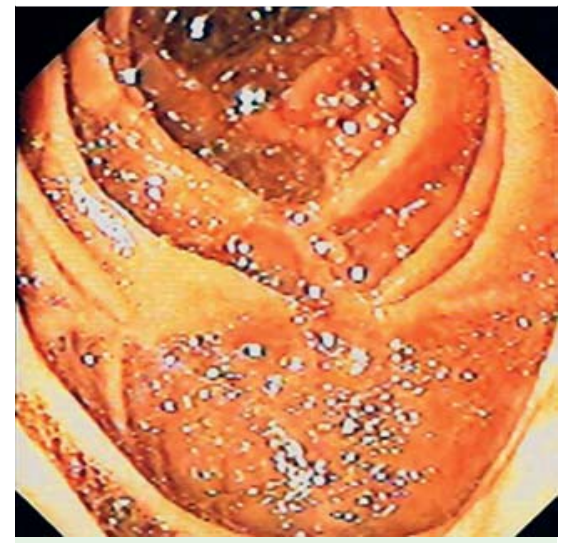

Fig. 3 Endoscopic appearance of the second portion of the duodenum, 6 months later, showing complete disappearance of the lesions and a normal appearance of the duodenal folds.

anemia, and weight loss ( $6 \mathrm{~kg}$ in 2 months). Gastroscopy found large ulcers in the second portion of the duodenum, with reduction of duodenal folds ( Fig. 1). The result of histological examination of the specimens was compatible with active Crohn's disease ( $\bullet$ Fig. 2 ), and computed tomography excluded any other gastrointestinal localization. The patient started treatment with azathioprine $2.5 \mathrm{mg} / \mathrm{kg}$ per day, pantoprazole $80 \mathrm{mg} /$ day, and adalimumab (160 mg at week 0 and $80 \mathrm{mg}$ at week 2 to induce remission, followed by maintenance treatment with 40 mg every 2 weeks). She responded immediately to the therapy, with immediate epigastric pain relief. Her weight recovered within 4 months, and all laboratory tests became normal within 3 months. At the first endoscopic follow-up (February 2010) we noted complete healing of the large ulcers and restoration of histology, which persisted until the last follow-up (August 2010) ( Fig. 3). At the present date the patient is still taking pantoprazole $40 \mathrm{mg}$ / day and adalimumab 40 mg every 2 weeks (azathioprine was discontinued after 6 months), and is in complete remission.

Anti-TNF $\alpha$ therapy has hitherto been regarded only as an alternative therapy for severe or refractory disease [2-4]. This is the first case report describing successful treatment of adult primary duodenal Crohn's disease with adalimumab. The case is also interesting because we used adalimumab as the first therapeutic strategy on appearance of the disease. This "top-down" approach resulted in more rapid remission than the conventional "step-up" treatment, with a faster reduction in clinical symptoms, rapid decline in laboratory inflammatory markers, and rapid endoscopic mucosal healing without the use of steroids [5].

Endoscopy_UCTN_Code_CCL_1AB_2AZ_3AC

Competing interests: None

\section{A. Tursi}

Gastroenterology Service, ASL BAT, Andria (BAT), Italy

\section{References}

1 Ando T, Nobata K, Watanabe $O$ et al. Abnormalities in the upper gastrointestinal tract in inflammatory bowel disease. Inflammopharmacology 2007; 15: $101-104$

2 Dignass A, Van Assche G, Lindsay JO et al. for the European Crohn's and Colitis Organization (ECCO). The second European evidence-based Consensus on the diagnosis and management of Crohn's disease: current management. J Crohn Colitis 2010; 4: $28-62$

3 Odashima M, Otaka M, Jin M et al. Successful treatment of refractory duodenal Crohn's disease with infliximab. Dig Dis Sci 2007; 52: $31-32$

4 Knapp AB, Mirsky FJ, Dillon EH, Korelitz BI. Successful infliximab therapy for a duodenal stricture caused by Crohn's disease. Inflamm Bowel Dis 2005; 11: 1123-1125

5 Lin MV, Blonski W, Lichtenstein GR. What is the optimal therapy for Crohn's disease: step-up or top-down? Expert Rev Gastroenterol Hepatol 2010; 4: 167-180

\section{Bibliography}

DOI $10.1055 / \mathrm{s}-0030-1255893$

Endoscopy 2011; 43: E22

(c) Georg Thieme Verlag KG Stuttgart · New York. ISSN 0013-726X

\section{Corresponding author}

\section{A. Tursi, MD}

Servizio di Gastroenterologia Territoriale

DSS No. 4, ASL BAT

Via Torino, 49

70031 Andria (BA)

Italy

Fax: +39-0883-1978210

antotursi@tiscali.it 